\title{
O papel do enfermeiro frente a casos de morte encefálica e doação de órgãos e tecidos
}

\author{
The role of the nurse in front of cases of brain death and donation of organs and tissues \\ El papel de las enfermeras en casos de muerte encefálica y donación de órganos y tejidos
}

Recebido: 27/01/2021 | Revisado: 02/02/2021 | Aceito: 09/02/2021 | Publicado: 13/02/2021

\author{
Loyane Barbosa dos Santos Furtado \\ ORCID: https://orcid.org/0000-0003-0219-5705 \\ Universidade Paulista, Brasil \\ E-mail: loyane.7.barbosa@gmail.com \\ Iel Marciano de Moraes Filho \\ ORCID: https://orcid.org/0000-0002-0798-3949 \\ Universidade Paulista, Brasil \\ E-mail: ielfilho@yahoo.com.br \\ Thais Vilela de Sousa \\ ORCID: https://orcid.org/0000-0002-7498-516X \\ Universidade Federal de Goiás, Brasil \\ E-mail: thais.fen@hotmail.com \\ Jéssica Guimarães Rodrigues de Roure \\ ORCID: https://orcid.org/0000-0002-4185-8076 \\ Universidade Federal de Goiás, Brasil \\ E-mail: jessicag.r@hotmail.com \\ Thaís Pereira Lima \\ ORCID: https://orcid.org/0000-0002-6657-2998 \\ Universidade Paulista, Brasil \\ E-mail: Thais0202lima@gmail.com \\ Aline Aparecida Arantes \\ ORCID: https://orcid.org/0000-0002-8882-2345 \\ Universidade Federal de Goiás, Brasil \\ E-mail: alenrantes@hotmail.com \\ Reginaldo Martins da Silva \\ ORCID: https://orcid.org/0000-0003-2320-5036 \\ Universidade Federal de Goiás, Brasil \\ E-mail: enfermagemclinica@gmail.com \\ Mayara Cândida Pereira \\ ORCID: https://orcid.org/0000-0002-0242-6262 \\ Universidade Paulista, Brasil \\ Francidalma Soares Sousa Carvalho Filha \\ ORCID: https://orcid.org/0000-0001-5197-4671
Universidade Estadual do Maranhão, Brasil \\ E-mail: francidalmafilha@gmail.com
}

\begin{abstract}
Resumo
Objetivo: Descrever o desempenho do enfermeiro no processo de morte encefálica e na doação de órgãos e tecidos. Método: Trata-se de um estudo de revisão narrativa da literatura com abordagem qualitativa exploratória voltada para atuação do enfermeiro em casos de morte encefálica e doação de órgãos. Resultados: Foram selecionados 14 artigos de acordo com o tema, após a interpretação foram divididos em duas categorias: a conduta da enfermagem frente ao possível doador com morte encefálica e diante a família dos pacientes com morte encefálica. Conclusão: O enfermeiro se apresenta como um otimizador de todo o processo de doação de órgãos e tecidos, ademais de ter um papel importante na busca ativa e na manutenção de pacientes com morte encefálica, além de se articular com os familiares na tentativa de obter uma decisão favorável à doação. A entrevista de enfermagem mostrou-se como um instrumento preditor que, se direcionado de maneira efetiva e humanizada, é capaz de evitar uma recusa familiar na tomada de decisão frente à doação.

Palavras-chave: Morte encefálica; Obtenção de tecidos e órgãos; Cuidados de enfermagem; Tomada de decisão; Família.
\end{abstract}

\begin{abstract}
Objective: To describe the nurse's performance in the brain death process and in the donation of organs and tissues. Method: This is a study of narrative review of the literature with an exploratory qualitative approach, focused on the role of nurses in cases of brain death and organ donation. Results: 14 articles were selected according to the theme, after the interpretation divided into two categories: nursing conduct facing and possible cause of brain death and
\end{abstract}


facing a family of patients with brain death. Conclusion: The nurse presents as an optimizer of the organ and tissue donation process and an important role in the active search and maintenance of patients with brain death, in addition to articulating with family members in an attempt to obtain a favorable decision to donate. The nursing interview showed that it is a predictive instrument that directs the effective and humanized way and is capable of avoiding a family refusal to make decisions regarding donations.

Keywords: Brain death; Tissue and organ procurement; Nursing care; Decision making; Family.

\section{Resumen}

Objetivo: Describir el desempeño del enfermero en el proceso de muerte encefálica y donación de órganos y tejidos. Método: Se trata de un estudio de revisión narrativa de la literatura con un abordaje cualitativo exploratorio, enfocado en el rol del enfermero en los casos de muerte encefálica y donación de órganos. Resultados: Se seleccionaron 14 artículos de acuerdo a la temática, tras la interpretación se dividieron en dos categorías: conducta de enfermería hacia el posible donante con muerte encefálica y ante la familia de pacientes con muerte encefálica. Conclusión: El enfermero se presenta como un optimizador de todo el proceso de donación de órganos y tejidos, lleva un papel importante en la búsqueda activa y el mantenimiento de los pacientes con muerte encefálica, además de articularse con los familiares en un intento por obtener una decisión favorable a la donación. La entrevista del equipo de enfermería resultó ser un instrumento predictivo que, si se conduce de manera eficaz y humanizada, consigue evitar un rechazo familiar en la toma de decisiones sobre la donación.

Palabras clave: Muerte Encefálica; Obtención de Tejidos y Órganos; Atención de Enfermería; Toma de Decisiones; Familia.

\section{Introdução}

A Morte Encefálica (ME), segundo a Resolução Conselho Federal de Medicina $n^{\circ}$ 2.173/17, pode ser caracterizada como parada total das funções cerebrais de maneira irreversível por causas conhecidas e constatadas de modo indiscutível, qualificado por coma aperceptivo, somado a ausência de resposta motora supraespinhal e apneia (CFM, 1997).

Após a confirmação da ME, pode-se dar início ao processo para doação de órgãos e tecidos (OT). Estes são procedimentos cirúrgicos que consistem na substituição de OT de uma pessoa doente, o receptor, por outro OT saudável de um doador, vivo ou cadáver. O Brasil é destaque na área de transplantes, atrás apenas dos Estados Unidos da América (EUA). No Brasil, os transplantes são operacionalizados, em sua maioria, no sistema público de saúde, visto que em média, $96 \%$ dos procedimentos de todo o país são financiados pelo o Sistema Único de Saúde (SUS) (Brasil, 2001).

Os doadores podem ser classificados em duas categorias: doador vivo, pessoa que concorda com a doação de forma que não haja danos para a própria saúde, tais como doação de um dos rins, uma parte do fígado, medula óssea ou pulmão. Estes podem ser parentes até o quarto grau e cônjuges do receptor e em casos de doadores sem parentesco deve haver autorização judicial. Na segunda categoria estão os doadores não vivos, que são pacientes diagnosticados com ME, que na maior parte das vezes, são vítimas de traumatismo craniano ou acidente vascular cerebral (Brasil, 2001).

De acordo com a lei no 10.211 de 2001, a família é quem exclusivamente incide e decide acerca da retirada de OT. Assim, a decisão de doação ou não pode ser afetada por alguns fatores emocionais como desespero, o momento de choque, além da desconfiança com o pedido de doação, o sofrimento, a não aceitação da morte encefálica, esperança de que o familiar possa voltar à vida e ainda conflitos familiares no processo de decisão (Rossato et al., 2017).

Entre os motivos que impedem a doação e consequentemente, a manutenção da vida de outra pessoa, estão a contraindicação médica (15\%) e a parada cardiorrespiratória (8\%), no entanto, a recusa familiar predomina com cerca de $42 \%$ dos casos (Oliveira e Junior, 2018; MS, 2019; ABTO, 2019). No Brasil, entre janeiro e junho de 2019, segundo dados do Registro Brasileiro de Transplantes, foram notificados 5458 potenciais doadores, sendo que destes, apenas 1764 foram doadores efetivos (ABTO, 2019).

Os hospitais com mais de 80 leitos sendo públicos, privados ou filantrópicos, devem possuir uma Comissão IntraHospitalar de Doação de Órgãos e Tecidos para Transplante (CIHDOTT). Essas comissões aparelham os hospitais e treinam os profissionais para que possam identificar os possíveis doadores, dessa forma, facilita o diagnóstico de ME e por consequência, 
a doação. Essas comissões ainda são vinculadas com a Central de Transplante do Estado para estruturar o processo de doação e captação de órgãos e são responsáveis pela educação continuada dos colaboradores da instituição no que diz respeito a doação e transplantes de OT (MS, 2019).

O enfermeiro é um dos profissionais de saúde que compõe a CIHDOTT, responsável por realizar a entrevista com a família do doador, no tocante ao diagnóstico de ME. Também é responsável por esclarecer de maneira ética, moral e legal, o segmento de captagem e distribuição de OT a serem doados, esclarecendo e entendendo as dúvidas e opiniões dos familiares (Aranda et al., 2018; Resende \& Moraes Filho, 2020).

Embora o Brasil seja o segundo maior transplantador de OT do mundo, os transplantes realizados são insuficientes considerando a crescente lista de espera. Nesse sentido, a atuação do enfermeiro se faz cada vez mais importante e necessária para todo o processo de transplante de OT (Aranda et al., 2018; Araújo e Massarollo, 2014).

Tendo em vista toda essa problemática, este estudo teve como objetivo descrever o desempenho do enfermeiro no processo de morte encefálica e na doação de órgãos e tecidos. O estudo se faz relevante por contribuir com evidências que darão suporte para a implementação de estratégias que melhorem, naturalizem, otimizem e suavizem o processo de doação de OT uma vez que ajudarão na fixação de conhecimento dos enfermeiros no que diz respeito à temática.

\section{Metodologia}

Trata-se de um estudo de revisão narrativa da literatura com abordagem qualitativa. De acordo com o suporte teórico utilizado, os artigos de revisão narrativa são publicações que possuem um caráter amplo e se propõe a descrever o desenvolvimento de determinado assunto, sob o viés teórico ou contextual, mediante análise e interpretação da produção científica existente. Dessa forma, são apropriadas para descrever e discutir o desenvolvimento do "estado da arte" de um determinado assunto, no ponto de vista teórico ou contextual. Ademais, essa síntese de conhecimentos a partir da descrição de temas abrangentes favorece a realização de novas pesquisas (Rother, 2007; Pereira et al., 2018).

Assim, foram abordados artigos científicos sobre o papel dos enfermeiros em casos de ME e doação de OT, pesquisados através dos Descritores em Ciências da Saúde (DECS): "Morte encefálica", "Obtenção de tecidos e órgãos", "Cuidados de enfermagem", "Tomada de decisão" e "Família". A busca foi realizada em setembro de 2019 nas bases de dados Biblioteca Virtual Em Saúde (BVS); Literatura Latino-Americana e do Caribe em Ciências da Saúde (LILACS), Scientific Eletronic Library Online (SciELO) e em dados da Associação Brasileira de Transplante de Órgãos.

Foram incluídos no estudo os artigos e documentos publicados no período de 2014 a 2019, no idioma português, disponíveis na íntegra para leitura e com assunto pertinente ao tema proposto. Após a aplicação dos critérios de inclusão, foi realizada leitura dos títulos e resumos dos estudos para averiguar a pertinência ao tema e assim foram selecionados 14 artigos considerados pertinentes para esta revisão. Após essa etapa de seleção, os artigos que constituíram essa revisão passaram por uma etapa de leitura na íntegra e extração de dados o que tornou possível a análise do conteúdo, depuração e apresentação dos resultados e discussão que se seguem.

\section{Resultados e Discussão}

Dentro do recorte temporal compreendido entre os anos de 2014 a 2019, a Tabela 1 demonstra que houve um maior interesse pela temática no ano de 2014, seguido por declínio nos anos de 2015 a 2017, voltado a discutir a temática nos anos de 2018 e 2019 e o ano com a maior quantidade de publicações em relação ao tema foi em 2018 com 5 (35,74\%) publicações. 
Tabela 1 - Distribuição de publicações relacionadas a morte encefálica e doação de órgãos e tecidos (n=14). Brasil, 2020.

\begin{tabular}{ccc}
\hline Ano de publicação & Número de artigos & Porcentagem (\%) \\
\hline $\mathbf{2 0 1 4}$ & 3 & 21,42 \\
\hline $\mathbf{2 0 1 5}$ & 1 & 7,14 \\
\hline $\mathbf{2 0 1 6}$ & 2 & 14,28 \\
\hline $\mathbf{2 0 1 7}$ & 1 & 7,14 \\
\hline $\mathbf{2 0 1 8}$ & 5 & 35,74 \\
\hline $\mathbf{2 0 1 9}$ & 2 & 14,28 \\
\hline Total & 14 & 100 \\
\hline
\end{tabular}

Fonte: Autores.

No Quadro 1, observa-se as informações referentes aos 14 artigos que foram utilizados no processo de discussão do presente estudo, sendo eles categorizados por: título, autor, objetivo, método, conclusão e ano de publicação.

Com relação ao título dos artigos $14(100 \%)$ contemplavam a temática da revisão e permeavam os descritores selecionadas. Quanto aos objetivos indicados pelos autores, 9 (64,28\%) dos estudos demostram claramente o papel do enfermeiro em casos de morte encefálica e doação de órgãos e tecidos. Quanto à abordagem observa-se que 6 (42,85\%) se tratava de estudos exploratórios descritivos e em sua maioria de abordagem qualitativa. 
Quadro 1 - Distribuição dos artigos de acordo com o título, autores, objetivo, método, conclusão e ano de publicação (n=14).

Brasil, 2020.

\begin{tabular}{|c|c|c|c|c|c|}
\hline Título & Autor & Objetivos & Método & Conclusão & Ano \\
\hline $\begin{array}{l}\text { A enfermagem } \\
\text { e o paciente em } \\
\text { morte } \\
\text { encefálica na } \\
\text { UTI. }\end{array}$ & $\begin{array}{l}\text { Costa CR, } \\
\text { Costa LP, } \\
\text { Aguiar N. }\end{array}$ & $\begin{array}{l}\text { Identificar o papel da } \\
\text { equipe de enfermagem nos } \\
\text { cuidados prestados aos } \\
\text { pacientes em morte } \\
\text { encefálica nas unidades de } \\
\text { terapia intensiva, apontando } \\
\text { condutas indispensáveis à } \\
\text { manutenção do potencial } \\
\text { doador, assistência à família } \\
\text { e controle de todas as } \\
\text { funções vitais até o } \\
\text { momento da doação de } \\
\text { órgãos. }\end{array}$ & $\begin{array}{l}\text { Revisão } \\
\text { bibliográfic } \\
\text { a. }\end{array}$ & $\begin{array}{c}\text { Conclui-se que a equipe } \\
\text { intensivista desempenha papel } \\
\text { de grande relevância na } \\
\text { manutenção das funções vitais } \\
\text { do potencial doador, sendo } \\
\text { necessário embasamento a } \\
\text { respeito de todos os aspectos da } \\
\text { morte encefálica, conhecimento } \\
\text { científico e ético, pois a } \\
\text { viabilidade dos órgãos ou } \\
\text { tecidos a serem doados depende } \\
\text { diretamente de sua adequada } \\
\text { conservação. }\end{array}$ & 2016. \\
\hline $\begin{array}{l}\text { Experiências e } \\
\text { expectativas de } \\
\text { enfermeiros no } \\
\text { cuidado ao } \\
\text { doador de } \\
\text { órgãos e à sua } \\
\text { família. }\end{array}$ & $\begin{array}{l}\text { Moraes } \\
\text { EL, et al. }\end{array}$ & $\begin{array}{c}\text { Compreender as } \\
\text { experiências e expectativas } \\
\text { dos enfermeiros de } \\
\text { unidades de terapia } \\
\text { intensiva no cuidado ao } \\
\text { doador de órgãos para } \\
\text { transplantes e à sua família. }\end{array}$ & $\begin{array}{c}\text { Pesquisa } \\
\text { qualitativa, } \\
\text { com } \\
\text { abordagem } \\
\text { da } \\
\text { Fenomenolo } \\
\text { gia Social. }\end{array}$ & $\begin{array}{l}\text { O estudo mostrou que o } \\
\text { cotidiano dos enfermeiros de } \\
\text { terapia intensiva no cuidado às } \\
\text { famílias e aos doadores de } \\
\text { órgãos é permeado por } \\
\text { obstáculos que interferem no } \\
\text { processo de doação. Diante } \\
\text { desse cenário, tem-se como } \\
\text { expectativas oferecer uma } \\
\text { assistência intensiva ao doador } \\
\text { falecido e um cuidado } \\
\text { humanizado às famílias, } \\
\text { intencionando possibilitar a } \\
\text { aceitação da doação de órgãos } \\
\text { pelos familiares e viabilizar } \\
\text { órgãos para transplantes. }\end{array}$ & 2015. \\
\hline $\begin{array}{l}\text { Conflitos éticos } \\
\text { vivenciados por } \\
\text { enfermeiros no } \\
\text { processo de } \\
\text { doação de } \\
\text { órgãos. }\end{array}$ & $\begin{array}{l}\text { Araújo } \\
\text { MN, } \\
\text { Massaroll } \\
\text { o MKB }\end{array}$ & $\begin{array}{l}\text { Conhecer os conflitos éticos } \\
\text { vivenciados pelos } \\
\text { enfermeiros no processo de } \\
\text { doação de órgãos. }\end{array}$ & $\begin{array}{l}\text { Pesquisa } \\
\text { qualitativa } \\
\text { utilizando a } \\
\text { análise de } \\
\text { conteúdo de } \\
\text { Bardin. }\end{array}$ & $\begin{array}{l}\text { Os conflitos éticos vivenciados } \\
\text { pelos enfermeiros no processo } \\
\text { de doação de órgãos foram: a } \\
\text { dificuldade do profissional em } \\
\text { aceitar a morte encefálica como } \\
\text { morte do indivíduo, a não } \\
\text { aceitação em desconectar o } \\
\text { ventilador mecânico do paciente } \\
\text { em morte encefálica e não } \\
\text { doador de órgãos, o } \\
\text { desconhecimento para a } \\
\text { realização do protocolo de } \\
\text { morte encefálica, a falta de } \\
\text { comprometimento, o descaso no } \\
\text { cuidado com o potencial doador, } \\
\text { a escassez de recursos humanos } \\
\text { e materiais, a crença religiosa e } \\
\text { a falha na comunicação. }\end{array}$ & 2014. \\
\hline $\begin{array}{l}\text { Fragilidades na } \\
\text { atenção ao } \\
\text { potencial } \\
\text { doador de } \\
\text { órgãos: } \\
\text { percepção de } \\
\text { enfermeiros. }\end{array}$ & $\begin{array}{l}\text { Costa IF, } \\
\text { et al. }\end{array}$ & $\begin{array}{l}\text { Conhecer a percepção de } \\
\text { enfermeiros sobre } \\
\text { fragilidades na atenção ao } \\
\text { potencial doador de órgãos. }\end{array}$ & $\begin{array}{l}\text { Exploratório } \\
\text {-descritivo, } \\
\text { com } \\
\text { abordagem } \\
\text { qualitativa, } \\
\text { do tipo } \\
\text { análise do } \\
\text { discurso. }\end{array}$ & $\begin{array}{l}\text { O estudo possibilitou conhecer a } \\
\text { percepção dos enfermeiros sobre } \\
\text { aspectos do processo de trabalho } \\
\text { na manutenção de PD e os } \\
\text { principais entraves, revelando } \\
\text { que os profissionais percebem } \\
\text { fragilidades, temem e sofrem as } \\
\text { repercussões no processo de } \\
\text { cuidar. }\end{array}$ & 2017. \\
\hline
\end{tabular}




\begin{tabular}{|c|c|c|c|c|c|}
\hline $\begin{array}{l}\text { A inserção do } \\
\text { enfermeiro na } \\
\text { comissão } \\
\text { hospitalar para } \\
\text { doação de } \\
\text { órgãos e } \\
\text { tecidos. }\end{array}$ & $\begin{array}{c}\text { Tolfo F, et } \\
\text { al. }\end{array}$ & $\begin{array}{c}\text { Conhecer como se dá a } \\
\text { inserção do enfermeiro em } \\
\text { comissão intra-hospitalar de } \\
\text { doação de órgãos e tecidos } \\
\text { para transplante, bem como } \\
\text { a obtenção de conhecimento } \\
\text { para sua atuação. }\end{array}$ & $\begin{array}{l}\text { Pesquisa } \\
\text { qualitativa, } \\
\text { descritiva e } \\
\text { exploratória, } \\
\text { com análise } \\
\text { de } \\
\text { conteúdo. }\end{array}$ & $\begin{array}{l}\text { Medidas educativas devem ser } \\
\text { inseridas na academia e serviços } \\
\text { de saúde, como forma de prover } \\
\text { subsídios necessários para que o } \\
\text { enfermeiro possa ter uma } \\
\text { participação mais efetiva nessas } \\
\text { comissões. }\end{array}$ & 2018. \\
\hline $\begin{array}{c}\text { Manejo de } \\
\text { pacientes em } \\
\text { morte } \\
\text { encefálica }\end{array}$ & $\begin{array}{c}\text { Costa } \mathrm{N} \text {, } \\
\text { et al. }\end{array}$ & $\begin{array}{l}\text { Analisar o conhecimento } \\
\text { dos enfermeiros da } \\
\text { Emergência e Unidade de } \\
\text { Terapia Intensiva em } \\
\text { relação ao manejo do } \\
\text { paciente em Morte } \\
\text { Encefálica. }\end{array}$ & $\begin{array}{l}\text { Abordagem } \\
\text { quantitativo, } \\
\text { descritivo e } \\
\text { exploratório } \\
\text {. }\end{array}$ & $\begin{array}{c}\text { O conhecimento dos } \\
\text { enfermeiros entrevistados } \\
\text { acerca do manejo com o } \\
\text { potencial doador é deficitário, } \\
\text { sendo necessárias capacitações a } \\
\text { respeito do tema. }\end{array}$ & 2018. \\
\hline $\begin{array}{l}\text { Comissão Intra- } \\
\text { Hospitalar de } \\
\text { Doação de } \\
\text { Órgãos e } \\
\text { Tecidos para } \\
\text { Transplante: } \\
\text { vivência dos } \\
\text { enfermeiros. }\end{array}$ & $\begin{array}{l}\text { Silva TR, } \\
\text { et al. }\end{array}$ & $\begin{array}{c}\text { Compreender as vivências } \\
\text { de enfermeiros da Comissão } \\
\text { Intra-Hospitalar de Doação } \\
\text { de Órgãos e Tecidos para } \\
\text { Transplante (CIHDOTT) } \\
\text { em uma instituição } \\
\text { hospitalar privada da Zona } \\
\text { da Mata Mineira. }\end{array}$ & $\begin{array}{l}\text { Estudo } \\
\text { descritivo e } \\
\text { qualitativo } \\
\text { com análise } \\
\text { de } \\
\text { conteúdo. }\end{array}$ & $\begin{array}{c}\text { O estudo demonstrou que a } \\
\text { vivência na comissão é } \\
\text { permeada por fragilidades e que } \\
\text { a identificação delas propicia o } \\
\text { desenvolvimento de estratégias } \\
\text { para aprimoramento do processo } \\
\text { nas instituições. }\end{array}$ & 2018. \\
\hline $\begin{array}{l}\text { Conhecimento } \\
\text { da equipe de } \\
\text { enfermagem } \\
\text { acerca dos } \\
\text { cuidados com o } \\
\text { potencial } \\
\text { doador em } \\
\text { morte } \\
\text { encefálica. }\end{array}$ & $\begin{array}{l}\text { Silva } \\
\text { TRBN, } \\
\text { Maicon } \\
\text { AS, Mota } \\
\text { AM. }\end{array}$ & $\begin{array}{l}\text { Analisar o conhecimento da } \\
\text { equipe de enfermagem } \\
\text { acerca das suas atribuições } \\
\text { na assistência ao paciente } \\
\text { em morte encefálica e } \\
\text { potencial doador de órgãos } \\
\text { e tecidos. }\end{array}$ & $\begin{array}{l}\text { Abordagem } \\
\text { qualitativa, } \\
\text { prospectivo } \\
\text { e descritivo- } \\
\text { exploratório } \\
\text { com análise } \\
\text { de conteúdo } \\
\text { de Bardin. }\end{array}$ & $\begin{array}{l}\text { A partir dos achados, propõe-se } \\
\text { a realização de capacitações } \\
\text { contínuas das equipes de } \\
\text { enfermagem, entendendo que } \\
\text { esses momentos podem } \\
\text { proporcionar a construção } \\
\text { coletiva de conhecimentos, e } \\
\text { representam oportunidade e } \\
\text { espaço de importante } \\
\text { aprendizado. }\end{array}$ & 2016. \\
\hline $\begin{array}{l}\text { Doação de } \\
\text { órgãos e tecidos } \\
\text { e motivos de } \\
\text { sua na } \\
\text { efetivação. }\end{array}$ & $\begin{array}{l}\text { Bonetti } \\
\text { CE, et al. }\end{array}$ & $\begin{array}{c}\text { Descrever características do } \\
\text { processo de doação de órgãos } \\
\text { e tecidos e identificar fatores } \\
\text { determinantes para a sua não } \\
\text { efetivação. }\end{array}$ & $\begin{array}{l}\text { Estudo } \\
\text { descritivo, } \\
\text { transversal, } \\
\text { retrospectiv } \\
\text { o e } \\
\text { documental, } \\
\text { de } \\
\text { abordagem } \\
\text { quantitativa. }\end{array}$ & $\begin{array}{c}\text { O estudo proporcionou } \\
\text { conhecimento sobre os } \\
\text { principais motivos da não } \\
\text { doação de órgãos e tecidos do } \\
\text { paciente potencial doador, } \\
\text { contribuindo para o } \\
\text { desenvolvimento de estratégias } \\
\text { que potencializem esse } \\
\text { processo, direcionadas aos } \\
\text { fatores modificáveis, } \\
\text { identificados como sendo } \\
\text { limitantes para a efetivação da } \\
\text { doação. }\end{array}$ & 2014. \\
\hline $\begin{array}{l}\text { Perfil das } \\
\text { notificações das } \\
\text { comissões } \\
\text { intra- } \\
\text { hospitalares de } \\
\text { transplante de } \\
\text { órgãos e tecidos } \\
\text { em hospitais } \\
\text { escola do } \\
\text { interior de São } \\
\text { Paulo. }\end{array}$ & $\begin{array}{l}\text { Gomes } \\
\text { NL, et al. }\end{array}$ & $\begin{array}{l}\text { Conhecer o perfil dos } \\
\text { potenciais doadores em um } \\
\text { complexo hospitalar do } \\
\text { interior do estado de São } \\
\text { Paulo e verificar melhorias } \\
\text { no serviço de captação de } \\
\text { órgãos e tecidos após a } \\
\text { contratação de um } \\
\text { profissional treinado com } \\
\text { dedicação exclusiva. }\end{array}$ & $\begin{array}{c}\text { Estudo } \\
\text { descritivo. }\end{array}$ & $\begin{array}{l}\text { O setor onde ocorreu o óbito e o } \\
\text { grau de parentesco do familiar } \\
\text { foram as variáveis definidoras } \\
\text { do processo de doação de } \\
\text { órgãos. Observou-se um } \\
\text { aumento do processo de doação } \\
\text { após a contratação do } \\
\text { profissional treinado e com } \\
\text { dedicação exclusiva. }\end{array}$ & 2014. \\
\hline
\end{tabular}




\begin{tabular}{|c|c|c|c|c|c|}
\hline $\begin{array}{l}\text { Significados } \\
\text { do cuidado } \\
\text { de } \\
\text { enfermagem } \\
\text { ao paciente } \\
\text { em morte } \\
\text { encefálica } \\
\text { potencial } \\
\text { doador. }\end{array}$ & $\begin{array}{l}\text { Magalhãe } \\
\text { s ALP, et } \\
\text { al. }\end{array}$ & $\begin{array}{c}\text { Compreender os } \\
\text { significados do cuidado ao } \\
\text { paciente em morte } \\
\text { encefálica potencial doador } \\
\text { para enfermeiros, e } \\
\text { construir um modelo } \\
\text { teórico. }\end{array}$ & $\begin{array}{l}\text { Estudo } \\
\text { qualitativo } \\
\text { sustentado } \\
\text { na Teoria } \\
\text { Fundamenta } \\
\text { da nos } \\
\text { Dados. }\end{array}$ & $\begin{array}{l}\text { O significado do cuidado ao } \\
\text { paciente em morte encefálica } \\
\text { potencial doador está em } \\
\text { entender sua complexidade para } \\
\text { além de um ser morto, mas } \\
\text { como gerador de vida por meio } \\
\text { da doação de órgãos. }\end{array}$ & 2018. \\
\hline $\begin{array}{l}\text { Potencial } \\
\text { doador cadáver: } \\
\text { Causas da não } \\
\text { doação de } \\
\text { órgãos. }\end{array}$ & $\begin{array}{l}\text { Correia } \\
\text { WLB, et } \\
\text { al. }\end{array}$ & $\begin{array}{l}\text { Conhecer as causas de não } \\
\text { concretização da doação de } \\
\text { órgãos de potenciais } \\
\text { doadores em um hospital de } \\
\text { referência. }\end{array}$ & $\begin{array}{l}\text { Estudo } \\
\text { descritivo, } \\
\text { documental } \\
\mathrm{e} \\
\text { retrospectiv } \\
\text { o, com } \\
\text { abordagem } \\
\text { quantitativa. }\end{array}$ & $\begin{array}{c}\text { O conhecimento dessas } \\
\text { situações oferece elementos que } \\
\text { norteiam a atuação das equipes } \\
\text { de captação de órgãos, no que } \\
\text { diz respeito à sensibilização da } \\
\text { população. }\end{array}$ & 2018. \\
\hline $\begin{array}{l}\text { Percepção de } \\
\text { familiares sobre } \\
\text { a doação de } \\
\text { órgãos e } \\
\text { tecidos. }\end{array}$ & $\begin{array}{l}\text { Santos } \\
\text { JIR, et al. }\end{array}$ & $\begin{array}{l}\text { Compreender as percepções } \\
\text { de familiares a respeito da } \\
\text { doação de órgãos e tecidos. }\end{array}$ & $\begin{array}{l}\text { Estudo } \\
\text { qualitativo, } \\
\text { exploratório } \\
\text { e descritivo } \\
\text { com Análise } \\
\text { de Conteúdo } \\
\text { de Bardin. }\end{array}$ & $\begin{array}{c}\text { Constatou-se o pouco } \\
\text { conhecimento e entendimento } \\
\text { sobre a doação de órgãos, sendo } \\
\text { esse resultado um reflexo de } \\
\text { vários fatores, como a baixa } \\
\text { discussão sobre o tema no meio } \\
\text { social. }\end{array}$ & 2019. \\
\hline $\begin{array}{c}\text { Processo de } \\
\text { morte } \\
\text { encefálica: } \\
\text { Significado } \\
\text { para } \\
\text { enfermeiros de } \\
\text { uma unidade de } \\
\text { terapia } \\
\text { intensiva. }\end{array}$ & $\begin{array}{l}\text { Alves MP, } \\
\text { et al. }\end{array}$ & $\begin{array}{l}\text { Compreender como os } \\
\text { enfermeiros significam o } \\
\text { cuidado prestado ao } \\
\text { paciente no processo de } \\
\text { morte encefálica em uma } \\
\text { Unidade de Terapia } \\
\text { Intensiva. }\end{array}$ & $\begin{array}{c}\text { Pesquisa } \\
\text { qualitativa } \\
\text { com aporte } \\
\text { teórico- } \\
\text { metodológi } \\
\text { co na } \\
\text { Teoria } \\
\text { Fundament } \\
\text { ada nos } \\
\text { Dados. }\end{array}$ & $\begin{array}{l}\text { O enfermeiro está presente em } \\
\text { todas as etapas do processo e } \\
\text { tem papel importante na busca } \\
\text { ativa, na gestão e observação } \\
\text { atenta do cuidado de } \\
\text { enfermagem ao potencial } \\
\text { doador. }\end{array}$ & 2019. \\
\hline
\end{tabular}

Autores*: Textos com mais de três autores foram reduzidos com o uso da expressão "et al." a fim de melhor apresentar a tabela. Fonte: Autores.

Para melhor compreensão dos resultados, eles foram divididos em duas categorias temáticas: a conduta da enfermagem frente o possível doador com morte encefálica e a conduta da enfermagem diante da família desses pacientes.

\section{A conduta da enfermagem frente ao possível doador com morte encefálica}

De acordo com a resolução do Conselho Federal de Enfermagem no 292/2004, confere ao enfermeiro avaliar, planejar, executar, coordenar e supervisionar os procedimentos de enfermagem realizados aos doadores de OT, visto que, ele é responsável por sua equipe. Logo, também cabe ao enfermeiro fazer a busca ativa de potenciais doadores assim, é ele quem notifica a CIHDOTT e emprega a Sistematização de Assistência de Enfermagem ao processo de doação de OT (Araújo e Massarollo, 2014; Costa, Oliveira, Santos, Leal e Sousa, 2018).

O enfermeiro atuante na CIHDOTT tem um papel fundamental para a otimização das etapas relacionadas aos transplantes, sendo que ele realiza as funções de identificação dos potenciais doadores e a notificação junto a Central de Transplantes, monitora a hemodinâmica do doador, promove a ligação entre a equipe de transplante e a família, acompanhando o processo de retirada dos OT, a entrega do material à equipe da Central de Transplantes e por fim, se atenta à integridade do corpo do doador antes de adjudicar a família (Costa et al., 2017; Tolfo et al., 2018; Gomes, Faleiros, Anna, Chieratto, 2014).

Mesmo na ocasião dos familiares não autorizarem a doação dos OT, o enfermeiro deve fazer a notificação do potencial doador junto à CIHDOTT. As Unidades de Terapia Intensiva (UTI) e as unidades de emergências são setores dos 
quais costumeiramente ocorrem a transição de um potencial doador em doador efetivo. Por conseguinte, o enfermeiro destes setores, como responsável pela supervisão dos cuidados prestados pela equipe ao potencial doador, também tem a necessidade de conhecer as alterações fisiológicas do paciente com ME para que, unido com a equipe, possam realizar um controle apropriado. Para tanto, deve haver programas de educação continuada para toda a equipe, abordando todo o processo de doação (Costa et al., 2017; Tolfo et al., 2018; Costa et al., 2018; Alves et al., 2019).

Nesse contexto, os profissionais envolvidos no procedimento de ME e doação de OT precisam, além de educação continuada, desenvolver habilidades e competências em comunicação interpessoal, aprender sobre aspectos éticos, conhecer protocolos para a doação de OT. Devem também ter envolvimento com todo o processo de maneira que transmita segurança para a família, o que pode evitar a recusa referente a doação de OT (Costa et al., 2018; Moraes, Neves, Santos, Merighi, Massarollo, 2015).

A situação de ME é definida como um processo complexo que desencadeia complicações prejudiciais para o potencial doador. Devido alterações endócrinas, metabólicas e hemodinâmicas há possibilidade de falência múltipla de órgãos, o que pode impossibilitar as doações. Destarte, uma equipe de enfermagem capacitada para detectar prováveis complicações, o enfermeiro deve ter conhecimento científico e firmeza em sua prática assistencial para proporcionar um cuidado de qualidade, que mantenha a estabilidade do potencial doador de órgãos e tecidos (Costa, Costa, Aguiar, 2016; Araújo e Massarrollo, 2014; Moraes et al., 2015).

De tal modo, o cuidado ao paciente em ME é iniciado com uma minuciosa revisão histórica, clínica e social, além de detalhado exame físico, posto que tumores no sistema nervoso central, intoxicações e uso de drogas podem ser a causa da ME. Desse modo, entre as intervenções vistas como primordiais na conservação do paciente em ME destacam-se a: hidratação das córneas, monitoramento da temperatura, controle dos sinais vitais, realização das dosagens de eletrólitos e da gasometria, duas hemoculturas e uma urocultura no início do protocolo. Com os devidos controles hemodinâmicos e fisiopatológicos é possível evitar complicações, como arritmias, disfunções cardíacas e coagulopatias (Tolfo et al., 2018; Bonetti et al., 2017; Gomes et al., 2014).

É imprescindível estabelecer uma manutenção eficiente, uma adequada preservação hemodinâmica e fisiológica do paciente com ME, assim é possível garantir a efetividade da doação para tal quadro. A enfermagem deve estar em constante aprendizagem, pois o enfermeiro tem um papel significativo gerando um ensejo de uma nova vida para muitos receptores (Gomes et al., 2014; Moraes et al., 2015).

\section{A conduta da enfermagem frente a família dos pacientes com morte encefálica}

Após o fechamento do protocolo de ME é efetivada a aproximação familiar com o intuito de provável doação de OT. Esse é um momento de muita fragilidade, considerando o grande impacto emocional que pode causar relutância familiar na tomada de decisão. O conhecimento sobre ME por parte dos familiares ainda é muito escasso e por isso, é a principal causa da recusa familiar, sendo seguido por questões religiosas, entrevista familiar mal realizada, desejo de conservar a integridade do corpo e até mesmo por desconhecer o desejo do potencial doador em vida. Os motivos do déficit de conhecimento sobre ME podem ser ocasionados pela inexistência de estudos sobre o assunto e há pouca divulgação, gerando desconfiança em relação ao diagnóstico (Costa et al., 2017; Tolfo et al., 2018; Silva, Alves, Carbogim, 2018; Santos, Santos, Lira, Moura, 2019; Silva, Nogueira, Sá, 2016).

Dessa forma, no momento de desolação dos familiares, sinais como temperatura do corpo do paciente, presença de batimentos cardíacos dificultam ainda mais a percepção de ME, já que o familiar, na maioria das vezes, ainda acredita que o paciente pode voltar à sobrevida. Diante disso, se faz importante a presença da família no processo de apuração da ME, fazendo com que o diálogo não seja a única forma de conclusão do caso, mesmo com a manifestação do desejo de doar em 
vida, no Brasil prevalece a decisão dos familiares, por isso se faz necessário oferecer assistência emocional além de ofertar informações sobre todo o processo. Portanto, o enfermeiro deve proporcionar cuidados para o potencial doador e para os familiares, visto que dessa forma há maiores oportunidades de consentimento da doação dos OT (Costa et al., 2017; Silva et al., 2018; Santos et al., 2019; Moraes et al., 2015; Correia et al., 2018; Moraes-Filho, Carvalho-Filha, Viana, 2019; Sousa et al., 2020; Almeida, Bueno, Baldissera, 2014).

À vista disso, se fazem necessárias campanhas educativas permanentes com o intuito de incentivar que os doadores compartilhem com a família a decisão de ser doador a fim de reduzir recusa. Ao abordar os familiares, o enfermeiro deve prestar informações claras. Para isso, o profissional deve desenvolver habilidades em comunicação. Quando há uma boa relação com a família do possível doador, dá-se uma situação favorável à tomada de decisão positiva (Silva et al., 2018; Santos et al., 2019; Silva et al., 2016; Magalhães et al., 2018; Alves et al., 2019; Moraes et al., 2015; Correia et al., 2018; MoraesFilho et al., 2019; Sousa et al., 2020; Almeida et al., 2014).

Do mesmo modo, na entrevista familiar o enfermeiro deve prestar informações fidedignas quanto ao diagnóstico de ME, esclarecer sobre o anonimato do doador e receptor, salientar sobre a necessidade de manutenção do corpo na UTI, informar sobre a possível interrupção em caso de parada cardíaca, informar os principais exames a serem realizados, como: exame clínico por dois médicos no intervalo de uma hora; teste de apneia; exames complementares como angiograma cerebral; eletroencefalograma; doppler transcraniano e cintilografia de perfusão cerebral que constataram a ME. Assim, os enfermeiros assumem o papel de educadores com o intuito de otimizar a melhoria na relação entre equipe, família e paciente. Entretanto, também se faz necessário proporcionar o tempo indispensável para a família entender a situação de morte e não apenas ofertar informações, cada um tem seu tempo individual para o processamento dessa nova realidade (Costa et al., 2017; Tolfo et al., 2018; Magalhães et al., 2018; Moraes et al., 2015).

Em resumo, os enfermeiros necessitam estar munidos de explicações simples e claras considerando os aspectos sociocultural dos familiares, para que seja assegurado o bom entendimento do assunto antes da discussão a respeito da doação. Compete salientar que a entrevista familiar é de suma importância, pois nela é possível estabelecer vínculo e obter confiança, o que facilita a efetivação da doação. Após instruir os familiares sobre o conceito de ME e o significado de doar, estes tendem a consentir a doação. Após a autorização da família, dá-se abertura ao protocolo interno que abrange procedimentos técnicos e administrativos que são necessários para assegurar a doação dos OT (Costa et al., 2017; Alves et al., 2019; Moraes et al., 2015; Correia et al., 2018; Moraes-Filho et al., 2019; Sousa et al., 2020; Almeida et al., 2014; Moreira, Pereira, Rodrigues, 2019).

\section{Considerações Finais}

O enfermeiro se apresenta como um otimizador de todo o procedimento de doação de órgãos e tecidos e possui um papel fundamental na busca ativa e na manutenção de pacientes com morte encefálica, além de se articular com os familiares a fim de obter uma decisão favorável a doação.

A entrevista de enfermagem mostrou-se como um instrumento preditor que, se direcionado de maneira efetiva e humanizada, se mostra eficaz e é capaz de evitar recusa familiar na tomada de decisão frente a doação. No intuito de desconstruir paradigmas e consequentemente, aumentar a probabilidade de doação, é necessário ao enfermeiro estar em constante aprendizado e desenvolver técnicas e habilidades ao abordar os familiares, propiciando maior sobrevida a outros pacientes, posto que é o profissional em maior contato no cuidado ao paciente e sua família.

Apesar da discussão aqui trazida, ainda são necessários mais estudos e outras abordagens que elucidem os diferentes aspectos dificultadores do processo de doação, como questões de capacidade técnica e clínica de instituições hospitalares em fazer tanto a captação, quanto o implante desses OT, ou mesmo as questões biopsicossociais que envolvem a decisão para que se possa cada vez mais divulgar, estimular e ampliar a doação de órgãos e tecidos. 


\section{Referências}

Almeida, E. C., Bueno, S. M. V. \& Baldissera, V. D. A. (2014). A abordagem dialógica para a formação ética do enfermeiro no processo de doação de órgãos. Arq. Ciênc. Saúde UNIPAR, Umuarama. 18(1): 19-22.

Alves, M. P., Rodrigues, F. S. R., Cunha, K. S., Higashi, G. D. C., Nascimento, E. R. P. \& Erdmann, A. L. (2019). Processo de morte encefálica: Significado para enfermeiros de uma unidade de terapia intensiva. Rev Baiana Enferm. 33:e28033

Aranda, R. S., Zillmer, J. G. V., Gonçalves, K. D., Porto, A. R., Soares, E. R. \& Geppert, A. K. (2018). Perfil e motivos de negativas de familiares para doação de órgãos e tecidos para transplante. Rev. Baiana Enferm.32:e27560.

Araújo, M. N., \& Massarollo, M. C. K. B. (2014). Conflitos éticos vivenciados por enfermeiros no processo de doação de órgãos. Acta Paulista de Enfermagem. 27(3): 215-220. https://dx.doi.org/10.1590/1982-0194201400037

Associação Brasileira de Transplantes de Órgãos. Registro Brasileiro de Transplantes. (2019). Dados Numéricos da doação de órgãos e transplantes realizados por estado e instituição no período: janeiro / junho- 2019. São Paulo: ABTO.

Bonetti, C., Boes, A., Lazzari, D., Busana, J., Maestri, E. \& Bresolin, P. (2017). Organ and tissue donation and reasons for its non-realization. Journal of Nursing UFPE on line. 11(9): 3533-3541.

Brasil. Lei n 10.211 , de 23 de março de 2001. Altera dispositivos da Lei nº 9.434, de 04 de fevereiro de 1997, que dispõe sobre a remoção de órgãos, tecidos e partes do corpo humano para fins de transplante e tratamento. Diário Oficial da União. Brasília.

Conselho Federal de Medicina (BR). (1997). Resolução CFM no 1.480, de 8 de agosto de 1997. Dispõe sobre a caracterização de morte encefálica. Brasília: CFM.

Conselho Regional de Enfermagem (BR). (2004). Resolução nº 292 de 07 de junho de 2004. Rio de Janeiro: CRE.

Conselho Federal de Enfermagem (BR). (2009). Resolução n³58 de 15 de outubro de 2009. Brasília: CFE.

Correia, W. L. B., Alencar, S. E. M., Coutinho, D. T. R., Gondim, M. M., Almeida, P. C. \& Freitas, M. C. (2018). Potencial doador cadáver: Causas da não doação de órgãos. Enfermagem em Foco. 9(3): 30-34.

Costa, C. R., Costa, L. P., \& Aguiar, N. (2016). A enfermagem e o paciente em morte encefálica na UTI. Revista Bioética. 24(2): 368-373.

Costa, I. F., Mourão Netto, J. J., Brito, M. C. C., Goyanna, N. F., Santos, T. C. \& Santos, S. S. (2017). Fragilidades na atenção ao potencial doador de órgãos: percepção de enfermeiros. Revista Bioética. 25(1): 130-137.

Costa, N., Oliveira, L., Santos, A., Leal, H. \& Sousa T. (2018). Manejo de pacientes em morte encefálica. Journal of Nursing UFPE on line. $12(4)$ : 953961.

Gomes, N. L., Faleiros, R. N., Anna, R. S. \& Chieratto, C. L. D. (2014). Perfil das notificações das comissões intra-hospitalares de transplante de órgãos e tecidos em hospitais escola do interior de São Paulo. Cuidarte. Enferm. 8(2): 95-101.

Magalhães, A. L. P., Erdmann, A. L., Sousa, F. G. M., Lanzoni, G. M. M., Silva, E. L. \& Mello, A. L. S. F. (2018). Significados do cuidado de enfermagem ao paciente em morte encefálica potencial doador. Revista Gaúcha de Enfermagem. 39: e2017-0274.

Ministério da Saúde (BR). (2019). Comissão intra-hospitalar de doação de órgãos e tecidos para transplante. Brasília.

Moraes, E. L., Neves, F. F., Santos, M. J., Merighi, M. A. B. \& Massarollo, M. C. K. B. (2015). Experiências e expectativas de enfermeiros no cuidado ao doador de órgãos e à sua família. Rev. Esc. Enferm. USP. 49(spe2): 129-135.

Moraes Filho, I. M., Carvalho Filha, F. S. S. \& Viana, L. M. M. (2019). O que é ser enfermeiro? Revista De Iniciação Científica E Extensão. 2(2), 69-70.

Moreira, R. J. M., Pereira, M. C. \& Rodrigues, R. J. M. (2019). Atuação do enfermeiro na doação e transplantes de órgãos e tecidos. Revista JRG de Estudos Acadêmicos. 2(5): 348-359.

Oliveira, M. J. R. L. \& Morais Júnior, S. L. A. (2018). O enfermeiro x potencial doador de órgãos: Conceitos relacionados à religião. Revista Nursing. 21(241): 2218-2222.

Pereira, A. S., Shitsuka, D. M., Parreira, F. J. \& Shitsuka, R. (2018). Metodologia da pesquisa científica. 1ed. Ed: UAB/NTE/UFSM. Santa Maria (RS).

Resende, L. B. \& Moraes Filho, I. M. (2020). Câncer em idosos: revisão narrativa das dificuldades na aceitação da doença e no tratamento. Revista JRG Estudos Acadêmicos. 3(6); 159-169.

Rossato, G. C., Girardon-Perlini, N. M. O., Begnini, D., Beuter, M., Camponogara, S. \& Flores, C. L. (2017). Doar ou não doar: a visão de familiares frente à doação de órgãos. Rev. Min. Enferm. 21: e-1056.

Rother, E. T. (2007). Revisão sistemática X revisão narrativa. Acta Paulista de Enfermagem. 20(2), v-vi.

Santos, J. I. R., Santos, A. D. B., Lira, G. G. \& Moura, L. T. R. (2019). Percepção de familiares sobre a doação de órgãos e tecidos. Rev enferm UFPE online. 13(3): 578-86.

Silva, T., Alves, M., Braz, P., \& Carbogim, F. (2018). Comissão Intra-Hospitalar de Doação de Órgãos e Tecidos para Transplante: vivência dos enfermeiros. Revista Enfermagem UERJ. 26: e34120. 
Research, Society and Development, v. 10, n. 2, e0110212422, 2021

(CC BY 4.0) | ISSN 2525-3409 | DOI: http://dx.doi.org/10.33448/rsd-v10i2.12422

Silva, T. R. B., Nogueira, M. A. \& Sá, A. M. M. (2016). Conhecimento da equipe de enfermagem acerca dos cuidados como potencial doador em morte encefálica. Rev. Enferm UFPI. 5(4): 24-30.

Souza, T. V., Macedo, C. S., Fidelis, A., Bezerra, M. L. R., Carvalho Filha, F. S., Pereira M. C., Silva R. C., Reis, M. A., Gondim, M. C. \& Moraes Filho I. M. (2020). Modelos teóricos utilizados por enfermeiros para avaliação da família: reflexão teórica. Revista Eletrônica Acervo Saúde. $12(4)$ : e2614.

Tolfo, F., Camponogara, S., Montesinos, M. J. L., Siqueira, H. C. H., Scarton, J. \& Beck, C. L. C. (2018). La inserción del enfermero en la comisión intrahospitalaria de donación de órganos y tejidos. Enfermería Global. 17(2), 185-223. 